\title{
IMPLEMENTATION OF MULTI-CRITERIA DECISION MAKING IN PlanNing Traffic Systems
}

\author{
Rados Bozica, Rados Ante \\ Venit Exante d.o.o., Dvorniciceva 19, Zagreb 10000, Croatia \\ Sapienza Roma, Piazzale Aldo Moro 5, 00185 Roma, Italy
}

\begin{abstract}
Every modification of traffic system in certain area has a specific goal which is obtainable in various ways. Strategy development for the future of traffic systems represents a hardy and demanding job. Different options appear as a result of different forecasts and assumptions for variables that determine the markings of the traffic system. Looking at a generalized model of the traffic system it is easy to notice that within the system we have several elements appearing and they interact, and by doing so, they are responsible for optimal traffic system functioning. When you plan a traffic system it is necessary to assume, in advance, that the model will grow in the future and that certain parts of models of the general plan will be expanded. Hence, multi-criteria decision making presented itself as one of better solutions in traffic systems planning.
\end{abstract}

Keywords: Multi-Critieria Decision; Traffic Systems; Planning; Implementation; Strategy development
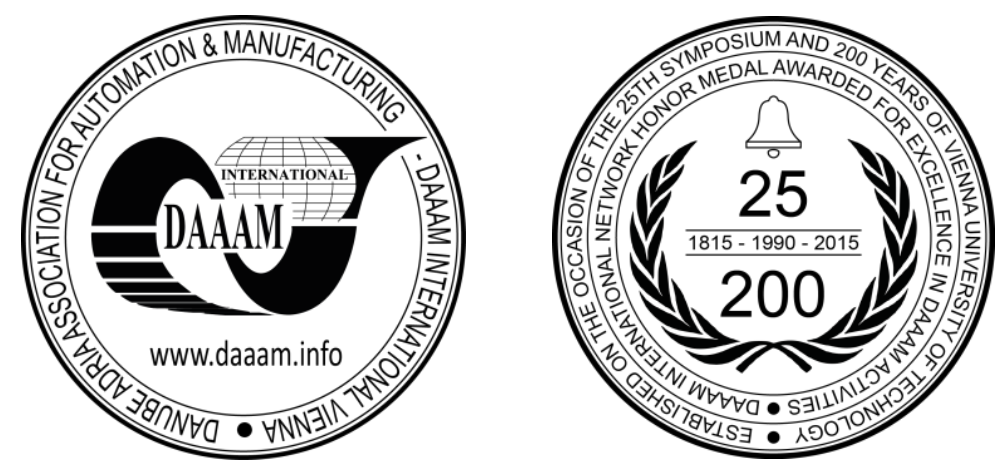

This Publication has to be referred as: Rados, B[ozica] \& Rados, A[nte] (2016). Implementation of multi-criteria decision making in planning traffic systems, Proceedings of the 26th DAAAM International Symposium, pp.0069-0074, B. Katalinic (Ed.), Published by DAAAM International, ISBN 978-3-902734-07-5, ISSN 1726-9679, Vienna, Austria DOI:10.2507/26th.daaam.proceedings.010 


\section{Introduction}

The complex issue of making decisions on transport infrastructure in different áreas is considered in the paper, and the use of multicriteria-analysis in this process is analysed. The analysis covers planning, design, maintenance and rehabilitation of transport infrastructure. Authors present conclusions on the possibilities, advantages, and limitations of the use of multicriteria-analysis methods, [1] with the purpose of improving quality of decision making regarding transport infrastructure in areas.

Traffic systems are units that encompass infrastructure and vehicles. When planning a new traffic system and/or restructuring the old one it is requiered, with previously set parameters that are within the project task i.e. function, purpose, to calculate and predict the behavior of the new or upgraded system [2]. The behavior is usually predicted to a time length of 30 years. These parameters are especially present in railway traffic system planning. The changes in the world traffic routes and globalization rendered the predictions of traffic system's flow growth almost impossible to make without the use of multi-criteria decision making.

Every modification of a traffic system in determined area is trying to obtain a certain goal. To this day various techniques have been developed in order to obtain this goal. Variability of these techniques is based on results obtained by forecasts, research and assumptions for variables that determine a certain traffic system [3]. Every measure, that is used to influence traffic system planning, has its value that synergistically influences goal function and criteria that are used to get to that goal. The specificity of traffic infrastructure is its substantial area that it covers within the cities. From 15 and up to $20 \%$ of cities area, and within cities centers more than $40 \%$, is occupied by traffic infrastructure which indicates a need for special attention whilst proceeding with new modifications on the old infrastructure.

Qualitative functioning of the traffic array depends on the quality of traffic service and, consequently, of the traffic infrastructure that with an adequate traffic system secures accessibility of city areas, and by doing that, elevating the value of the areas. Multi-criteria decision making whilst applied in the domain of traffic infrastructure reflects in the same time on the ones that have the authority in decision making and on the users of the system itself.

There is no one right transit decision. The best designed system will depend upon local conditions and local preferences. Geographical and physical situation, topological configuration, financing, know-how, technical capability, institutional capacity, and political constitute local conditions whilst low cost, high customer service level, rapid journey, convenience, comfort, frequent service, safety, and security constitute passengers' preferences [4]. Therefore selecting an appropriate mass transit system necessitates a multi criteria decision aid which will take all these conditions and preferences into consideration. The typical Multi-criteria decision making problem deals with the evaluation of a set of alternatives in terms of a set of decision criteria. [5].

When planning we can use different methods such as multi-criteria decion making.

Ultimate goal of decision making process:

- development and comparison of priorities

- identification and confirmation of a strategy which provides an optimal solution in near future.

In process of making a traffic plan it is required to:

- define goals and expenditures

- real assessment of current status

- vision of future situation

- $\quad$ solution development

- $\quad$ traffic model production and assessment frame specification

- $\quad$ investigation and assessment of traffic plan options

It is precisely multi-criteria decision making that enables a quality shift in traffic systems planning. The system is, in difference to models, an organized assembly of elements that act in service of a set goal. The system status is in any time determined by current status of all the components.

In traffic, and in planning of these multi-element systems, it is often that legal and financial conditions impede the use of these experiments to find an alternative traffic solution.

Because of this complicated nature of the problem on hand, it can be modeled as a network and treated with a network based multi criteria decision making approach. ANP is a new theory that extends the Analytic Hierarchy Process (AHP) to case of dependence and feedbacks introduced by Saaty [6]. with book in 1996 revised and extended in 2001. The ANP makes it possible to deal systematically with all kinds of dependence and feedback in decision system . ANP allows for complex interrelationships among decision levels and attributes. The ANP feedback approach replaces hierarchies with networks in which the relationship between levels are not easily represented as higher or lower, dominated or being dominated, directly or indirectly [7], [8]. For instance, not only does the importance of the criteria determine the importance of the alternatives, as in hierarchy, but the importance of the alternatives may also have an impact on importance of the criteria [9]. Saaty proposed ANP approach that can be utilized for examining network model representations. The power of ANP lies in its use of special ratio scales [10] to capture all kinds of interactions between tangible and intangible criteria for making accurate predictions and better decisions. Because of interactions 
among criteria, the criteria that are less important individually might turn out to be more important when evaluated collectively in a network [11].

In this paper we will try to explain the effect of potential traffic problems through the use of several techniques of operational research such as system dynamics and multicriteria decision aid. The purpose is mainly conceptual and methodological. The literature might be classified in different ways. We classify the literature based on two dimensions: content, methodology. [12]. It is planned to show how these techniques can be combined to provide new tools for investigating solutions and remedies to solve the congestion problem.

\subsection{Planning by applying the theory of decision making}

One of notable characteristics of the traffic system is interaction between traffic systems and its surroundings. Traffic represents an integral part of many social activities and as such produces the need for adequate traffic services and adequate system quality and quantity. Within the planning process of traffic systems there are many alternatives for future system changes. With numerous alternatives the problem becomes equally complex because it is needed to calculate all of the alternatives presented and to choose the best one or the one that optimally corresponds with criteria. When assessing the alternatives it is required to define the criteria that lead to the goal itself and potential influences for the change in the system.

Every specific alternative has its inner mechanisms hence they cause problems in decision making process. Authors [13] have developed a generic methodology for designing control policies in complex socio-economic systems, called Adaptive Control Methodology (ACM). It was fully indicated to develop an alternative approach within this more general framework.

The ACM consists of four main phases comprising each several steps (11 steps in all):

1. Information system - Mental modelling phase;

2. System Dynamics modelling phase;

3. Strategy building and MCDA phase;

4. Monitoring and Control phase.

The purpose of phase 4 is to update the policy decisions as a function of the monitoring of their efficiency. So it is essentially where the iterative aspects set in during the day-to-day optimisation process, until stationary distributions of departure times are obtained.

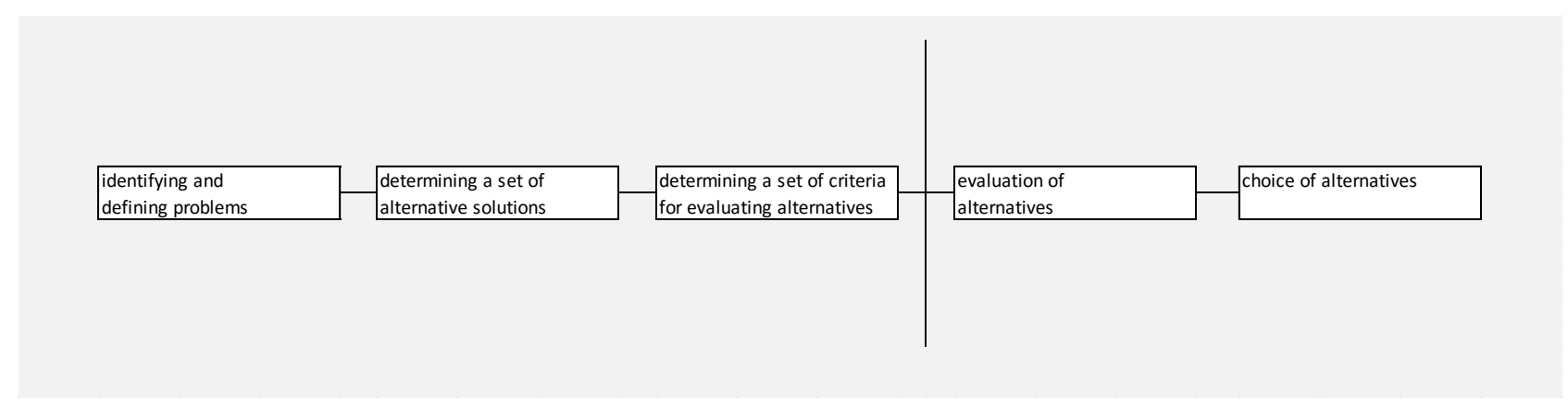

Fig. 1. Problem structure and analysis

In phase 3, in which strategies are fixed, a MCDA-driver shall trigger a myriad of individual departure decisions. This is based on the ideas explained in Macharis [14] in which the author proposes the direct blending of the MCDAcalculations into the equations of the SD-model. As a matter of fact the system we are modelling incorporates the varying behaviour of car commuters in making their choice of a departure time.

The peculiarity of the transposition of this technique to the current problem is that it has to deal with a large number of decisionmakers, i.e. car commuters. Hence, it is necessary to treat the problem by means of distributions of behaviours as pointed before.

Often it is very hard to determine the criteria by which it will be possible to determine the best strategy. Because of that it is necessary to structure and analyze the problem (Fig.1.). The changes in the system are often pressed by limited time for implementation and it is necessary to include economic indicators of cost effectiveness within the assessment (Fig.2.). 


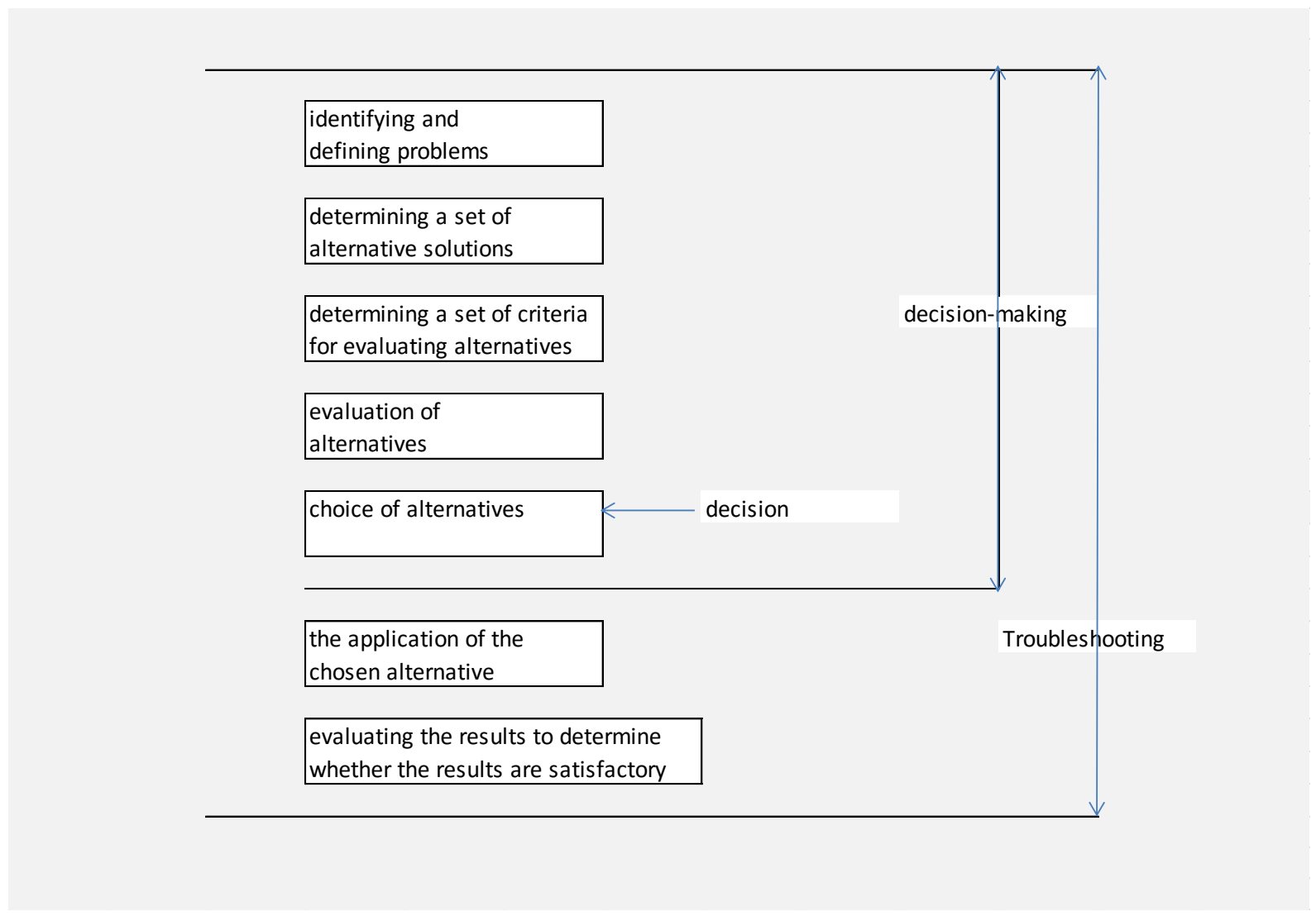

Fig 2. Relation between problem solving and decision making

\section{Role and significance of managing in traffic system}

Basic task of managing in traffic system is to define the following parameters: system goals for a determined time, conditions in which the system will function and ascertain how the goals will be obtained. Functioning in space and time the traffic system is always changing. Having that in mind it is clear that no system can survive without management.Existence of control subsystem is a condition for traffic system functioning.Managing contains activities that enable better adjustment of the traffic system to today's economy and conditions. Traffic system is an open system where management has limited possibility of regulation of its behavior because there are no special elements for precise predictions of economic conditions and the same results of that functioning [15]. In traffic system there is absolutely no possibility to predict with absolute certainty certain causes and effects of those causes. The reason for this is simple for there are numerous causes that are working within the system but weren't taken in consideration when the planning of the same system was taking place. Due to partial acquaintance with the causes it is impossible to set the principles i.e. laws of conduct of the system. The in determinability of traffic system behavior conditions continued decision making in management process and it requires a constant input of information about system functioning.For management status assessment we can use Saaty scale (system of criteria evaluation by numerical values) which gives us the possibility of scale assessment and comparison of two or more management forms.

\section{Decision making problem}

Decision making about management form is easily modeled by following components:

1. $\quad$ Current status (available resources)

2. Transformation process (alternatives, operators)

3. $\quad$ Aimed (final) status (goal)

\section{Quantitative analysis and decision making}

Quantitative analysis is based on primarily manager assessments, his experience and intuition. If the manager in question doesn't have enough experience in solving current problems then the quantitative analysis becomes necessary. The role of quantitative analysis is especially important in solving complex decision making problems. 


\section{Discussion}

Within the process of planning traffic objects or systems there are predefined elements in spatial plans and the space for development of individual variables, all very different between themselves, is limited. It is probably the reason why in the planning phase there is significantly lower usage of multi-criteria decision making. When comparing planning solutions they are analysed from an economic-engineering point of view or, in other words, through method of cost and benefit analysis. There are cases, when making a decision about financing certain projects, where using the method of cost and benefit is inadequate. This resulted in application of certain elements of multi-criteria decision making alongside cost and benefit analysis. The World Bank uses this mixed method for its own economic-engineering model for evaluating projects of traffic infrastructure [16]. Within european countries there is a development of models for traffic project's assesment that no longer exclusively depend on cost and benefit analysis and include multi-criteria analysis $[17,18]$.

Decision making process is a very broad term and it moves from basic routine decisions up to long term decisions. Considering the fact that key decisions and activities in modern business are made in precarious and extremely complex conditions, keeping in mind enormous influence and long term consequences on business success, this problem is given special attention today. In contemporary work and life conditions decision making is incomparably more frequent and more intense than ever before. The capability of decision making is a skill that is learned and perfected with time and experience.

Decision making is a process that takes less or more time in which the choice is made between two or more possibilities of how to resolve the problem.Business decisions can't be made based on intuition, they require more systemic approach. Rational theory of decision making is known also as normative or mathematic theory. This theory was developed during World War 2 and it was used for solving war problems and later for managerial decision making. Rational decision making is based on analytical approach that is composed of certain phases and it is used in situations that are non-recurrent. This decision making requires an informed manager and it is connected with scientific methods. Since it is connected with scientific methods it can also be referred as scientific decision making.

Rational decision making has the following phases:

- problem definition

- versions generation and evaluation

- versions selection

- application of selected versions

- control of the results

In recent times in business decision making we have information technology. Bearing in mind the fact that traffic as a discipline is an extremely dynamic activity we can produce long-term effects by adequately monitoring and modeling traffic. Since traffic is closely tied with finances application of quality programs connected to its monitoring and managing can reduce significantly any potential harmful consequences. [19].

Whilst determining the optimal solution of traffic problem it is necessary to define a relative criteria. Multicriteria decision making enables optimization regarding several criteria and improves the quality of decision making process. The process represents an optimization of goal function within a group of certain possible solutions. The manager is presented with a large number of solutions where he proceeds to evaluate, compare and rank received results.

Problems of multi-criteria decision making are divided in two categories:

- optimal choice methods

- optimization with several goal functions methods

Problems of multi-criteria decision making are also used in determining the way of management of the traffic system.

Data processing is done by using knowledge basis in observed process, based on accumulated data about traffic status, where we get two sets of data. One set is giving information to other participants in traffic while the other is used to enable process management. In this paper the analysis of the initial hypothesis of positioning of the corridor model in operational level is made. Corridor model represents a simplified representation of the real world in which all of the characteristics of the problem in question are comprised. Models have to contain system characteristics which is analyzed in a way to be understandable and easy to use and yet still provide sufficient results. The model must contain all characteristics that are relevant in problem solution $\square 20 \square$. Depending on model structure it is possible to employ different classifications (analog, symbolic, mathematic). If there is a detail list of all the characteristics that occur within the observed traffic system it is likely that they will produce almost perfect description of the process. In reality this is nearly impossible and it would require certain simplifications and limitations to enable it. From processed entry parameters it is obvious that the maximum attention will be given to synergy between technical and organizational part. The synergy obtained will result in increased security and satisfactory system functioning. 


\section{Conclusion}

With the term "multi-criteria decision making" in this paper it is emphasized that planning process of the traffic system is undoubtedly the most important function in securing its survival. Multi-criteria decision making is a sum of current actions or actions during the period of system modification with a goal to realize management i.e. system goals. For exact method implementation in traffic system management it is required to have a system model, system goal and a sum of permissible managerial functions. Multi-criteria decision making is done by influencing the management parameters by changing their values.

In this paper we have tried to demonstrate on the traffic problem the necessity to combine several techniques with system dynamics modelling. This necessity is imposed by the nature of the problem itself since there are different time scales. Although we were not able to present simulation results here, due to the fact that several parts of the model need to be validated, the basic structure of the model is clear and allows us to understand the process which cause the traffic jams in the morning.

One may conclude that if one wants to "solve" (partially) the traffic problem, it is the departure distribution, created by some statistical decision process of the car commuters from the suburbs, which should be spread out by introducing new cost-functions for these decision makers.

Certain limitations in application of multi-criteria analysis reside within the complexity of criteria importance definition. We can conclude that the method of multi-criteria analysis, provided that there are well defined entry parameters, can substantially contribute to the quality of traffic infrastructure planning process. In these conditions the methods of multi-criteria analysis improve decision making as they provide objectivity, transparency and the possibility of control of the actual decision making process.

\section{References}

[1] Sarkis, J.,Quantitative models for performance measurement system-alternate considerations, International Journal of Production Economics, 86, 2002, pp. 81-90.

[2] Hasan, M. A., Shankar, R., Sarkis, J., Supplier selection in an agile manufacturing environment using data envelopment analysis and analytical network process, International Journal of Logistics Systems and Management, 2008, Vol. 4, No. 5, pp. 523-550.

[3] Ballou, D., Wang, R., Pazer, H., and Tayi, G. K., Modeling information manufacturing systems to determine information product quality, Management Science, 1998, Vol. 44. No. 4, pp. 462-484.

[4] Boroushaki, S. and Malczewski, J., Implementing an extension of the analytical hierarchy process using ordered weighted averaging operators with fuzzy quantifiers in ArcGIS, Computer and Geosciences, 2008, Vol. 34, pp. 399-410.

[5] Velasquez,M., Hester. T.P. An Analysis of Multi-Criteria Decision Making Methods, International Journal of Operations Research, 2013. Vol. 10, No. 2, 56-66.

[6] Brans, J.P., Vincke, Ph. and Marechal, B., How to select and how to rank projects: The PROMETHEEmethod, European Journal of Operational Research,1986, 24, 228- 238.

[7] Lee A. H. I., Chen, W. C.,Chang, C. J., A fuzzy AHP and BSC approach for evaluating performance of IT department in manufacturing industry in Taiwan, Expert Systems 'with Application, 2008, Vol. 34, pp. 96-107.

[8] Saaty, R. W.,The analytical hierarchy process (AHP) for decision making and the analytical network process (ANP) for decision making with dependence and feedback, Creative Decisions Foundation, 2003.

[9] Faisal, M. N., Banwet, D. K., Analysis alternatives for information technology outsourcing decision: an analytic network process approach, International Journal of Business of Information Systems, 2009, Vol. 4, No. 1, pp. 4762.

[10] Chung, S. F., Lee, A. H. L., and Pearn, W. L.., Analytical network process (ANP) approach for mix planning in semiconductor fabricator, International Journal of Production Economics, 2005, 96, pp. 15-36.

[11] Hwang, S. N., An application of data envelopment analysis to measure the managerial performance of electronics industry in Taiwan, International Journal of Technology Management, 2007, Vol. 40, No, 1/2/3, pp. 215-228.

[12] Saaty, T. L., Rank from comparisons and from ratings in the analytichierarchy/network processes, European Journal of Operational Research, Vol. 168, 2006, pp. 557-570.

[13] Rezaei, J. A Systematic Review of Multi-criteria Decision-making Applications in Reverse Logistics, 18th Euro Working Group on Transportation, EWGT 2015, 14-16 July 2015, Delft, The Netherlands: Transportation Research Procedia ,10.pp. 766 - 776.

[14] Lee, J. W. and Kim, S. H., An integrated approach for independent information system projection, International Journal of Project Management, 19, 2001, pp. 111-118.

[15] Chen, Y. W., Formulation of a Learning Analytical Network Process, Proceeding of the Sixth International Symposium on The AHP, ISAHP 2001,(Bem-Switzerland), pp. 73-78.

[16] Fiala, P. and Jablonsky, J., Performance Analysis of Network Production System by ANP Approach, Proceeding of the Sixth International Symposium on the AHP, ISAHP 2001, (Bem-Switzerland),2001, pp. 101-103.

[17] Saaty, T. L., The Analytic Network Process: Decision Making With Dependence and Feedback, RWS Publications, Pittsburgh, 2001.

[18] Chang, D. Y.. Applications of the extent analysis method on fuzzy AHP,European Journal of Operation Research, 1996, Vol. 95, pp. 649- 655.

[19] Erensal, Y. C., Oncan, T. and Demircan, M. L., Determining key capabilities in technology management using fuzzy analytic hierarchy process: a case of Turkey, Information Science, 2006, Vol. 176, pp. 2755-2770.

[20] Anand, M. D., Kumanan, T.S.S, Johnny, M. A., Application of multi-criteria decision making for selection of robotic system using fuzzy analytic hierarchy process, International Journal of Management and Decision Making, Vol. 9, No. 1, 2008, pp. 75-98. 